\title{
Correction to: Are the ergogenic effects of photobiomodulation therapy age-dependent? A randomized double-blinded placebo-controlled trial
}

\author{
Carolina Gassen Fritsch ${ }^{1}$ - Laura Ayang Folgiarini ${ }^{1}$ • Natália Sgarioni Gomes ${ }^{1}$ - Marco Aurélio Vaz ${ }^{2}$. \\ Bruno Manfredini Baroni ${ }^{1}$
}

Published online: 30 May 2019

(C) Springer-Verlag London Ltd., part of Springer Nature 2019

\section{Correction to: Lasers in Medical Science} https://doi.org/10.1007/s10103-019-02790-9

The author name Bruno Menfridini Baroni was incorrectly captured in the original article. The correct author name is Bruno Manfredini Baroni.

The original article has been corrected.

The online version of the original article can be found at https://doi.org/ 10.1007/s10103-019-02790-9

Carolina Gassen Fritsch

carolinafritsch@gmail.com

1 Universidade de Ciências da Saúde de Porto Alegre (UFCSPA),

Porto Alegre, RS, Brazil

2 Universidade Federal do Rio Grande do Sul (UFRGS), Porto

Alegre, RS, Brazil 